This article was originally published in:

L. Evans \& R. C. Schwing (Eds.). Human behavior and traffic safety

(pp. 485-520). New York: Plenum Press, 1985.

It is based on a paper presented at a General Motors Symposium, held September

23-25, 1984, at the GM Research Laboratories, Warren Michigan.

It is reproduced here with minor typographical corrections and stylistic alterations.

The page numbering follows that of the original.

\title{
A CRITICAL VIEW OF DRIVER BEHAVIOR MODELS: WHAT DO WE KNOW, WHAT SHOULD WE DO?
}

\author{
John A. Michon \\ University of Groningen \\ The Netherlands
}

There appears to be a lack of new ideas in driver behavior modeling. Although behavioral research is under some pressure, it seems too facile to attribute this deplorable state of affairs only to a lack of research funds. In my opinion the causal chain may well run in the opposite direction. An analysis of what is wrong has led me to the conclusion that human factors research in the area of driver behavior has hardly been touched by the "cognitive revolution" that 'swept psychology in the past fifteen years. A more cognitive approach might seem advisable and the "promise of progress" of such an approach should be assessed.

The past twenty years have, of course, given us many insights that will remain applicable, provided they can be made to fit a cognitive frame of reference. The major categories of models of the past two decades are reviewed in order to pinpoint their strengths-and perhaps their weaknesses-in that framework. This review includes such models as McKnight \& Adams' task analysis, Kidd \& Laughery’s early behavioral computer simulations, the linear control models (such as McRuer \& Weir's), as well as some more recent concepts such as Näätänen \& Summala's, Wilde's and Fuller's risk coping models which already carry some cognitive weight.

What can we take from these conceptualizations of driver behavior and what is it that they are lacking thus far? Having proposed my answers to these questions an attempt is made to formulate an alternative approach, based on production systems as developed by J.R. Anderson. 


\section{INTRODUCTION}

The Purpose of This Paper- For this paper I was asked by the organizing committee of the symposium to critically review driver behavior models. I see it as my job not to offer you the impossible, which is the ultimate integration of' the hundreds of driver model studies that have been reported in the past. A document retrieval scan did readily convince me of the ungainliness of that task. Try one yourself! The librarian who was patient enough to help me, repeatedly pointed out to me that retrieving all 15129 or 12996 or 4489 abstracts that could be found under "model" and "driver" and "behavior" would obfuscate rather than clarify the issue even if one would discount such fascinating items as "Investigation of Planar, Two-Dimensional Ejectors with Periodic Steady Supersonic Driver Flow” (AD-POOO 517/3 B3026843). So, let us make life simpler: not the detailed content of the model literature, but an inventory of what they claim to be their contribution to a general theory of driving would seem to make sense, but it is still a lot.

I was also invited, however, to answer the double question: What do we know and what should we do? Taken separately the first part of the question could indeed be understood as an invitation to explain what we know now that we did not yet know, let us say, twenty years ago. The answer would give us an idea about progress or the lack of it, about the robustness of some models and the frailty of others, and so on. The second part of the question, on the other hand, requires that we already know what we are heading for with driver behavior modeling. In combination the two questions imply that we find out to what extent what we know adds to what we should do, and so the first question simply reduces to: What useful things do we know? This again makes life more comfortable for a critical reviewer, provided that he knows the answer to the second part of the question.

Fortunately I know that answer: We are heading for an intelligent, knowledge and rule based model of the driver that will be capable of dealing with a wide variety of realistic, complex situations. In other words, we are heading for a psychologically plausible expert system or, if you like, a robot driver. At least, that is what we should be heading for.

What Happened to Driver Behavior Research? - Something happened to driver behavior research, or perhaps I should say that something did not happen. Twenty years ago there was a bustling activity in this research area and quite a few interesting, novel approaches to the formulation of driver behavior were introduced at that time (see e.g. Forbes, 1972; Shinar, 1978). More recently, however, efforts seem to have lost much of the excitement and the momentum of the sixties.

This impression was reinforced when I received the program for the 1984 Annual Meeting of the Transportation Research Board (TRB). As a matter of fact, the program promised very little that might be considered relevant for driver behavior modeling, and indeed few of the "great names" seemed to be involved at all. The meeting itself confirmed my suspicions. Generally speaking 
colleagues agreed and as an explanation some of them put the blame for this sad situation upon a lack of research funds. Now, there can be no doubt that the behavioral sciences are under some financial pressure. But there would seem to be no reason why driver behavior research should be particularly vulnerable in this respect.

Traffic safety is, by and large, a politically stable issue and no party-left, right or center-could easily afford to oppose it. Traffic accidents are still on the order of the day and the annual damages to the community are simply shocking. In a country as small as The Netherlands they run, according to a recent but not yet published study by the National Road Safety Research Institute, into the equivalent of 4 billion US dollars annually. ${ }^{*}$ ) On a per capita basis this amounts to 300 US dollars annually.

But, could it perhaps be that the prevailing doldrums are the cause rather than the effect of funding policy? More than one 'spokesperson' at the TRB Meeting acknowledged that as a definite possibility. Could it therefore be that there are not enough interesting ideas around which merit grant support on a wider scale? Could it, for one thing, be that we have in the past twenty years reached a level of precision in our models that make further improvements relatively uninteresting? Or have we perhaps failed to incorporate enough other, highly important aspects of driver behavior besides those that already received attention in the sixties?

In my view the answer to any and all of these questions is a qualified yes. Much of the work in the area of driver behavior modeling is not relevant for a cognitive approach to the driving task. And thus, yes, there is not enough research money available and an important reason is that there are not enough new ideas around to strike our fancy (and that of granting agencies). And, yes, some of our best but at the same time most restrictive models will resemble hairsplitting as much as anything else... to most administrators, that is. And most emphatically, yes, we have been unable to incorporate a sufficiently wide range of interesting driver behaviors in our models.

Of course, I must produce adequate support for these imputations. That will be my aim for the next section of the present contributions. More important, however, than proving one's case is demonstrating that there are indeed interesting and untried answers to the question: What should we do?” That will be my task in the third section of this paper.

\section{WHAT DO WE KNOW?}

The Cognitive Stance - I wish to raise one more matter of policy. After all, we are considering what we should do, and what I wish to say might be a part of those considerations. Over the past twenty years the behavioral sciences, and

\footnotetext{
* At the exchange rate of June 1st, 1984.
} 
psychology in particular, have gone cognitive. Human factors research, has not quite kept up with this trend, having had considerable difficulty shedding its behaviorist past. (The European approach to ergonomics, incidentally, appears to have suffered considerably less in this respect.)

At last January's TRB Meeting, I could not help but be struck by the absence of cognitive talk among the driving investigators who were present, in both the paper sessions and the committee meetings. This confirms another recent experience. On a journey that brought me to the major centers of research in artificial intelligence and information science in this country (ACRIT, 1984), I was informed more than once that graduates from the classical human factors programs are not really competitive for jobs in their own field with graduates in cognitive psychology from schools that have a strong program in the latter field. I realize, of course, that human factors jobs in such fields as robotics, or library and information sciences may be different from the average human factors job. But, maybe this is an indication that something is missing in human factors curricula that ought not to be missing.

Travel and Traffic: Hierarchical Connections- For what other reasons should driver research go cognitive? Are there intrinsic, problem-specific reasons why we should turn to cognitive science instantly? I think there are, and the distinctly hierarchical cognitive control structure of human behavior in the traffic environment - and in a wider sense the mobility and communication context-is one of them.

Human mobility is embedded in a social as well as in a technological environment, and traffic and transportation issues should be treated in terms of the characteristics of a system in which the human being is only one of the many components, albeit an important one. The most characteristic feature of the

\begin{tabular}{|c|c|c|c|c|}
\cline { 2 - 5 } \multicolumn{1}{c|}{} & \multicolumn{4}{c|}{ Behavioral Level } \\
\cline { 2 - 5 } \multicolumn{1}{c|}{} & $\mathbf{I}$ & $\mathbf{I}$ & $\mathbf{I I}$ & I V \\
\hline $\begin{array}{c}\text { Human Quality as } \\
\text { a Problem Solver }\end{array}$ & Road User & $\begin{array}{c}\text { Transportation } \\
\text { Consumer }\end{array}$ & Social Agent & $\begin{array}{c}\text { Psycho-Biological } \\
\text { Organism }\end{array}$ \\
\hline $\begin{array}{c}\text { Problem to be } \\
\text { Solved }\end{array}$ & $\begin{array}{c}\text { Vehicle } \\
\text { Control }\end{array}$ & Trip Making & $\begin{array}{c}\text { Activity Pattern } \\
\text { (Communication) }\end{array}$ & $\begin{array}{c}\text { Satisfaction of } \\
\text { Basic Needs }\end{array}$ \\
\hline Task Environment & Road & $\begin{array}{c}\text { Road Network } \\
\text { (Topographical } \\
\text { Structure) }\end{array}$ & $\begin{array}{c}\text { Socio-Economic } \\
\text { Structure }\end{array}$ & $\begin{array}{c}\text { Nature } \\
\text { (Environment) }\end{array}$ \\
\hline Task Aids & $\begin{array}{c}\text { Vehicles, } \\
\text { Signs, etc. }\end{array}$ & $\begin{array}{c}\text { Transport Mode } \\
\text { Transport } \\
\text { System }\end{array}$ & $\begin{array}{c}\text { "Culture", } \\
\text { Technology }\end{array}$ \\
\hline
\end{tabular}

Figure 1 The hierarchical structure of problem solving tasks in traffic and transportation (after Michon, 1976). 
human component in this system is its behavior as an intelligent if not quite infallible problem solver. Taking this point of view one may outline a descriptive framework which allows the specification of a number of basic tasks that together constitute the set of relations between people and the environment in which they attempt to satisfy their mobility needs. In this context it is possible to distinguish four stable levels at which the human being is in systematic interaction with the transport and traffic system as such (Michon, 1976; Michon and Van der Molen, 1976). These levels may be defined by reference to a person's role as an active road user, a transportation consumer, an active social being, and a psycho-biological organism satisfying a number of basic needs, respectively. Figure 1 specifies these four functional levels relative to the (problem solving) context in which they appear. One should keep in mind that these levels are coupled in what we can probably best be described as a nested hierarchy.

The generalized problem solving task of the driver-qua road user-may be further divided in three levels of skills and control: strategical (planning), tactical (maneuvering), and operational (control) respectively (Michon, 1971, 1979; Janssen, 1979).

The strategical level (see Figure 2) defines the general planning stage of a trip, including the determination of trip goals, route, and modal choice, plus an evaluation of the costs and risks involved. Plans derive further from general considerations about transport and mobility, and also from concomitant factors such as aesthetic satisfaction and comfort.

At the tactical level drivers exercise maneuver control allowing them to negotiate the directly prevailing circumstances. Although largely constrained by the exigencies of the actual situation, maneuvers such as obstacle avoidance, gap acceptance, turning, and overtaking, must meet the criteria derived from the

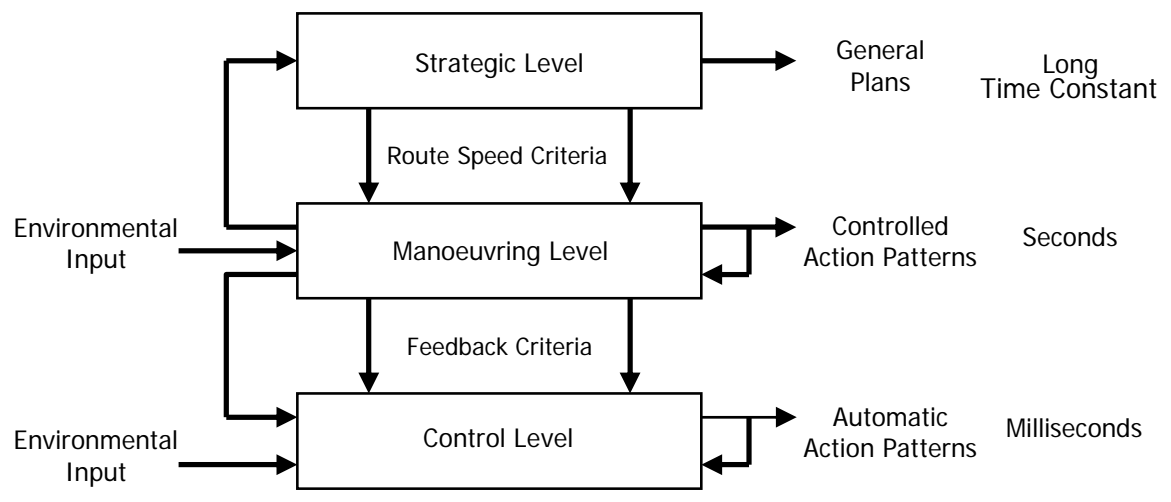

Figure 2 The hierarchical structure of the road user task. Performance is structured at three levels that are comparatively loosely coupled. Internal and external outputs are indicated (after Janssen, 1979). 
general goals set at the strategical level. Conversely these goals may occasionally be adapted to fit the outcome of certain maneuvers. A comprehensive model of driver behavior should not only take the various levels into account, but should also provide an information flow control structure that enables control to switch from one level to the other at the appropriate points in time.

Types of Driver Behavior Models- Models come any size and any disguise. Engineers and psychologists both use terms like, for instance, feedback or "open loop," but frequently such terms refer to different concepts altogether. Despite the variety of appearances, however, the number of different model types-or metamodels if you like-is limited.

I shall use a simple two-way classification (see Figure 3), in which we first distinguish between models that are input-output, or behavior oriented, and those that are motivation oriented. In this context motivation must be understood in its generic sense of "reason for moving" (cf. Dutch: beweegreden; German: Beweggrund). Let us distinguish, in the second place, between taxonomic and functional models which represent systems whose components respectively do and do not dynamically interact. I use the term taxonomic rather than structural because in modern usage the term structural does frequently imply dynamic processes (viz. self-organizing systems).

Every cell in the table of Figure 3 contains one or more model categories, each of which will be briefly discussed, with the following questions in mind. How successful have they been in the past: have they been generalized beyond their initial domain? And, how do they deal with cognition: do they specify internal states (representations) and the rules that operate on these internal states?

\begin{tabular}{|c|c|c|}
\cline { 2 - 3 } \multicolumn{1}{c|}{} & Taxonomic & Functional \\
\hline $\begin{array}{c}\text { Input-Output } \\
\text { (Behavioral) }\end{array}$ & Task Analyses & $\begin{array}{c}\text { Mechanistic Models } \\
\text { Adaptive Control Models } \\
- \text { Servo-Control } \\
- \text { Information Flow Control }\end{array}$ \\
\hline $\begin{array}{c}\text { Internal State } \\
\text { (Psychological) }\end{array}$ & Trait Models & $\begin{array}{l}\text { Motivational Models } \\
\text { Cognitive (Process) Models }\end{array}$ \\
\hline
\end{tabular}

Figure 3 Summary of driver behavior model types.

\section{TAXONOMIC MODELS: FACTS AND FACTORS}

A taxonomic model is essentially an inventory of facts. The pertinent relations that, in such a model, hold between these facts are those of sets: super- 
and subordination, identify, sequential relations (before, while, after) and measures on sets: proportions, likelihood or generalized distance. Although not necessarily more primitive than the other categories of models-the taxonomies, for instance, describing the "five kingdoms of life" (Margulis and Schwartz, 1982) appear as sophisticated at anything-taxonomic models have serious limitations. No dynamic relations can be expressed between the elements in a taxonomy and empirically connections are at best correlative. Taxonomic models of driver behavior are exemplified by trait models and by task analysis.

Trait Models - The story of classical test-based models (e.g. Conger et al., 1959) in driver research is well known. It is not in the last place the ongoing story of traffic safety's JR: the accident prone driver. Several authors have recently reviewed the rise and fall (and rise again) of this type of research (McKenna, 1982, 1983; Michon, 1984). Since there is little that could be of any use for a cognitive model of driver behavior, I will not repeat these reviews. Among the approaches that do deserve attention, however, is that of Fleishman (1967, 1975) who developed a factorial model for perceptual, cognitive, and motor skills. According to his model such skills result from the combination of a small number of elementary traits (e.g. reaction speed, spatial orientation). These combinations can be represented as vectors in a multidimensional space. As a result of development or learning, the dimensional structure of this space will change. When practicing a manual skill, for instance, the aptitude for verbalizing one's behavior will gradually become less important and finally may even disappear from the factor structure for that skill. The latter will be the case when performance attains a final state of automaticity. Although one of Fleishman's many concerns has been automobile driving, he never studied this task over time as a function of training or experience.

The thing that is of interest to the present discussion is the change which occurs when a subject is learning to perform a complex perceptual-motor task. Especially the shift from a more verbal to a more automatic performance, from "knowing that to knowing how," is important as it plays an eminent role in the present discussion about the acquisition of cognitive skills (e.g. Anderson, 1982). Fleishman's approach offers no insight in the actual processing involved in the performance of complex tasks, but it can be a valuable tool for tracing the overall stage of the learning process.

The second trait model I wish to mention is of a distinctly different nature. It depends on observations of accident frequency. It is based on principles that are commonly used in industrial quality control procedures (e.g. Shaw and Sichel, 1971). This involves measuring the time intervals between successive accidents or critical events. The assumption is that for each individual, intervals between stochastically independent critical incidents will show a distribution of which the parameters will remain stationary as long as the underlying generating processes remain stationary too. Personality variables, but also stress, illness and other factors may induce changes in the parameter pattern. This may alter the average interval between successive incidents or their variance, or both, while the changes may be gradual or continuous, slow or fast, periodic or irregular. 
Like Fleishman's factors, the stochastic parameter estimates proposed here could be used to gauge the information processing that occurs while driving.

Changes might be indicative of specific changes in the processing habits, at least if the quality control approach were extended to a more microscopic level than that of accidents. If anything it offers a systematic procedure for studying the occurrence of cognitive errors (see below).

Task Analysis - A driving task analysis is essentially a description of facts about the driving task (task requirements), the behavioral requirements (performance objectives), and the ability requirements (enabling objectives) for performing that task. The outstanding example in this category remains the task analysis by McKnight and Adams (1970a, 1970b; McKnight and Hundt, 1971), who partitioned the driving task in some 45 major tasks (including 9 off-road tasks such as vehicle maintenance), composed of altogether more than 1700 elementary tasks. Together the descriptions of these tasks constitute an exhaustive inventory of automobile driving. An example of these descriptions is the following fragment taken from Task 42.0: "Negotiating On-Ramps and Off-Ramps.” In Task 42-123 the driver "observes on-ramp/main roadway configuration when entering an on-ramp."

Task 42-123 Observes a general on-ramp/main roadway configuration

42-1231 Looks to see if on-ramp feeds into right side of main roadway or left side (speed lane) of main roadway

42-1232 Looks to see if acceleration lane is provided at end of on-ramp

42-1233 Looks for exit off-ramps or deceleration lanes which cross over or share continuing portions of the entrance ramp

42-1234 Evaluates effects of on-ramp/main roadway configuration on available merging distance and probable merging pattern

It may be mentioned in passing that the authors have specified their ability requirements (enabling objectives) analysis in term of required knowledge and required skills. The importance of this distinction for cognitive driver models was already stressed in the discussion of Fleishman's approach, in the preceding section.

In my view the effort of McKnight and Adams is one of the few truly important contributions to driver behavior modeling of the past twenty years, and it has been followed up in several other traffic tasks (e.g. motorcycle riding; pedestrian behavior (Van der Molen et al. 1981». It could very well serve as the database for a cognitive model that, by virtue of the scope of the analysis, would pretty well cover the lower two levels of the driver control hierarchy, that is, the tactical and the operational levels.

Of course this task analysis is not entirely unique, but data from more limited studies may easily be incorporated into McKnight and Adams' general frame of reference. Among these is the analysis which was proposed by Perchonok (1972) and later extended by Fell (1976) and others. These authors have paid special attention to performance failures. These are classified as belonging to four 
types: errors of perception, comprehension, decision and action, respectively. Performance errors have, in recent years, attracted considerable attention since they reveal, better than correct performance, where in the system processing bottlenecks are located (Norman, 1981). The reason for this popularity is that errors appear to be lawful events; even errors of speech, hesitations and slips of tongue have been shown to follow their own structural grammar (Levelt, 1983).

A further relevant line of research was introduced around 1965 by Quenault, which in fact was an attempt at combining task analysis and trait models. Quenault (1967; Quenault et at., 1968) developed a technique for systematic observation under fairly unrestrained normal driving conditions. He had his subjects drive along a predetermined standard route. An observer possessing a detailed knowledge of this route would accompany the subject and make a detailed protocol of a semiquantitative nature involving both the situation on the road and the behavior of the driver. On the basis of a number of summary scores derived from the protocols Quenault was able to distinguish between four types of driver: the safe driver, the injudicious driver, the dissociated active driver and the dissociated passive driver. The performance descriptions of these four driver types have a very high face validity, but there never accumulated much empirical support for them. There has been some application of this technique as a means of selecting candidates for a program of differentiated remedial driver training. With Quenault's approach we have perhaps a useful and in my opinion thus far undervalued basis for distinguishing types of drivers on the basis of concrete cognitive processing strategies.

\section{MECHANISTIC MODELS: UNSAFE AT ANY SPEED}

"Unsafe at any speed" would seem to epitomize the human driver considered as a mechanistic model. It is not surprising that this type of model has not gained much popularity in the field of driver behavior. Yet, some specific problems have been tackled successfully with them, particularly in the area of car following. The famous “Tunnel Studies” by Greenberg (1959) and by Edie and Foot (1960) undertook to describe the behavior of cars moving platoon-wise in a single lane as a problem of dynamics, and more particularly hydrodynamics. If, for some reason, a car in a platoon decelerates, capacity problems are likely to arise. Cars downstream will react to the occurring discontinuity by decelerating too, and in this way a shockwave will form and travel backwards through the platoon.

The limitations of such an approach are readily apparent. Herman and his associates at General Motors Research Laboratories were the first to relax the strict assumption that car platoons behave as an incompressible fluid (Herman et at., 1959). However, by introducing various assumptions about what it is that the driver wants to do, a model stops to be mechanistic, regardless of its terminological disguise. Thus Herman's assumption that drivers aim at minimizing the speed difference with the car in front of them, will take the car following model into the category of adaptive control models. 
Although most car following models now incorporate behavioral or motivational assumptions, the mechanistic models have not quite vanished (e.g. Alberti and Belli, 1978, following an early lead of Prigogine who applied some of Boltzmann's ideas about dynamic systems in disequilibrium of the car following problem).

\section{ADAPTIVE CONTROL MODELS}

The developments around the concept of adaptive control, beginning with the work of Wiener and Von Neumann in the nineteen forties, have inspired two lines of driver behavior modeling. The first deals primarily with manual control in the context of signals that are essentially continuous in time, at least in good approximation. The second line of research found its basis in the programmable digital computer and deals with the control of the flow of information in symbol processing machines. This approach deals essentially with discontinuous signals and abrupt decisions. In practice, however, the difference between these two ways of looking at signals-originally distinguished as analog and digital simulation-has disappeared due to the tremendous increase in computing speed of the digital computer. What has remained though, is the difference between the conceptual bases, and as a result some models are recognizable as hybrid models. Such is the case, for instance, with the DRIVEM model (Wolf and Barrett, 1978a, 1978b).

Servo-Control Models-Considering driving as a continuous or intermittent tracking task has proved to be a highly fruitful approach for modeling the low level steering skills involved in straight or curved road driving as well as for some simple obstacle avoidance maneuvers. Servo-control models act upon input signals which usually represent the lateral position of a vehicle on the road (compensatory tracking), or the road curvature, sometimes called the "visual scene" (pursuit tracking). Transfer functions representing both driver and vehicle dynamics, comprise lead and lag components in order to account for preview (anticipation) and sluggishness of driver reactions.

Many investigators have, especially during the early seventies, adopted the conceptual framework of adaptive dynamic control, first applied in extenso to driving by McRuer, Weir, and others at Systems Technology, Inc. (STI) (e.g. McRuer and Weir, 1969; Weir and McRuer, 1968). The model was published in 1967 and it is still alive and well: it has been improved several times (e.g. McRuer et al., 1977) and it has provided fundamental bricks for the majority if not all of the later steering models (Figure 4). Reid (1983) has actually suggested to use the STI-model as a benchmark against which to compare new driver models. This suggestion must certainly be very enjoyable for its originators, but at the same time it indicates the limited degrees of freedom this type of model apparently grants to model makers. Indeed, if we consider what has happened with this class of models since the sixties, one cannot fail to notice a very considerable refinement of the mathematical treatment (although methodologically 


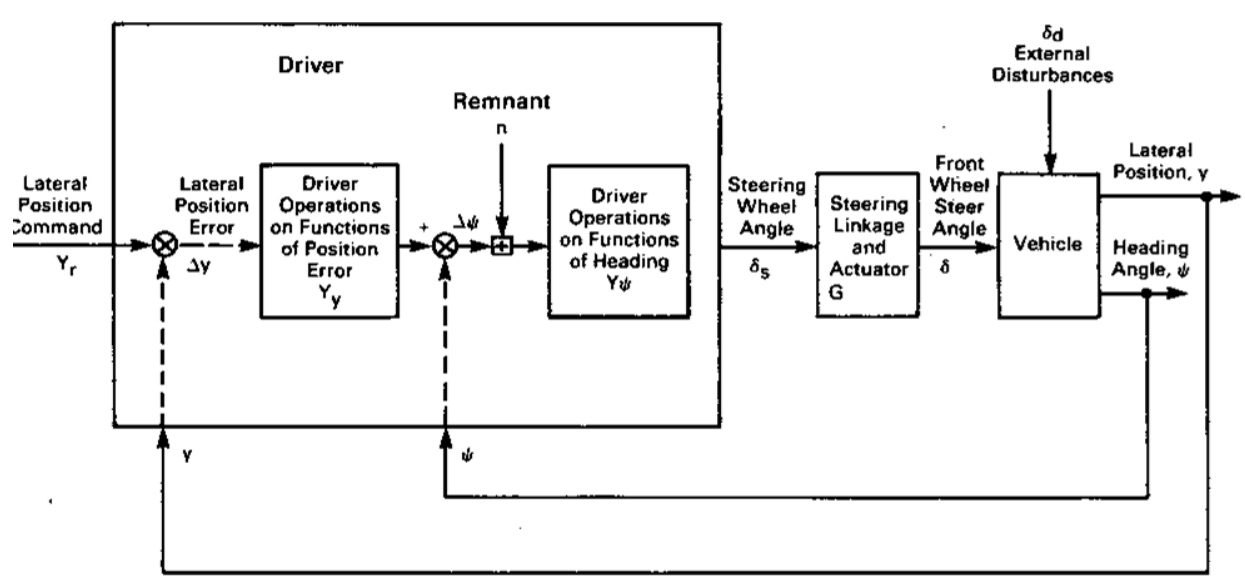

Figure 4 The STI compensatory driver model (after McRuer et al., 1977).

classical techniques tend to be favored rather than, for instance, the newer theory of optimal control). Whatever improvements there have been are in a very narrow range of tasks, however, and these find practically no ramifications into other aspects of the driving task.

In a recent review of driver steering models Reid (1983; p. 25) concluded that the prevailing dynamic control models do not yet successfully cope with driver tasks other than following straight and smoothly curved roads: "The model forms for other task scenarios are not yet fully developed. It is suggested, however, that a suitable form for the lane change and obstacle avoidance maneuver would be an initial precognitive open loop response followed by a closed-loop tracking response to stabilize the vehicle on its new course."

If you wish to find out what precisely a precognitive open loop response is, you may be surprised to find quite a few well-:documented examples already in the mid-sixties (Weir and McRuer, 1968; Preyss, 1968; Wierwille and Gagné, 1966; Young, 1969). Figure 5 is, in fact, taken from the 1969 paper by McRuer and Weir. Such a response involves stored "models" or representations of a series of possible future courses of the input signal, and these are switched on in turn whenever some appropriate pattern is detected in the input signal.

It seems as if little progress has been .made with precognitive models in the intervening period and what seems to be a promise now seemed very much to be a promise then. But this need not surprise us. Any information flow control system which incorporates standard algorithms for computing low level system outputs may in fact be regarded as having a precognitive open loop structure, even though it is not called by that name. Therefore, stressing this aspect as a suggestion for future developments is rather like worshipping a very pale ghost of the past.

I wish to point out that the "visual environment" which the existing servocontrol systems are declared to deal with also tends to be inexcusably pale (e.g. 


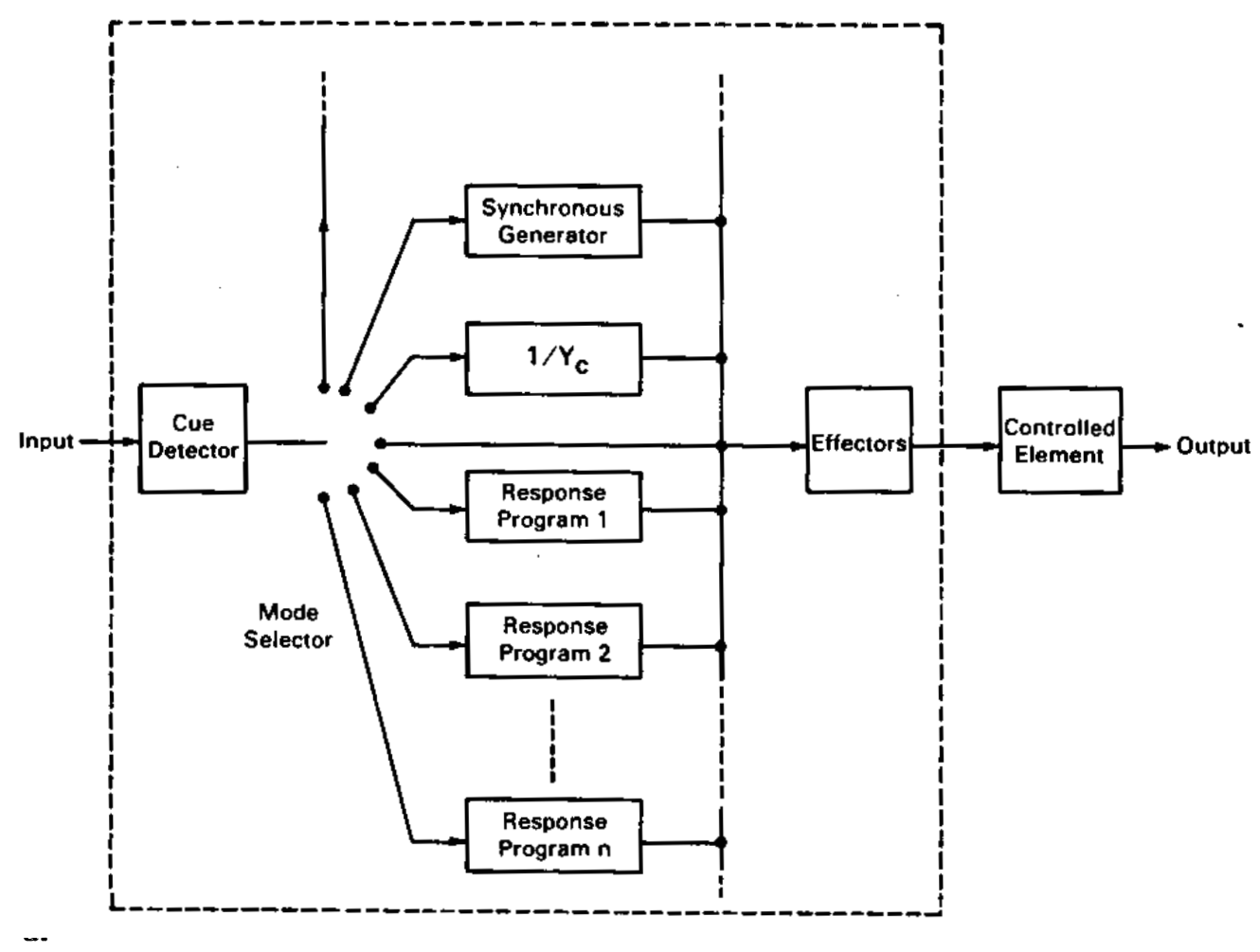

Figure 5 The principle of precognitive (open loop) control. Depending on an external cue signal one of the response modes (preprogrammed or learned) is selected.

Crossman and Szostak, 1968). Research in visual motion perception (see e.g., Wagenaar and Leibowitz, 1982) can provide a description of the ways in which the subject filters and reduces the inputs from a complex, dynamic environment, thus obtaining the required information about course speed and acceleration (e.g. Koenderink en Van Doorne, 1975; Riemersma, 1981) in the "ambient optical array" (Gibson; 1966). The two fields-perception and vehicle control are still lacking a theoretical integration. Combining them would constitute a major breakthrough, and it seems likely that the increasing importance of robotics will provide a new impulse for this problem, because here the connection of intelligent sensors and decision procedures with highly effectors is of fundamental concern.

Information Flow Control Models- Early attempts to simulate the driver by means of digital computer simulation were undertaken at Cornell Aeronautical Laboratories in Buffalo, NY. Kidd and Laughery (1964) were in charge of what became a quite complicated simulation program incorporating several of the major tasks facing the driver. Figure 6 represents a flow chart of one small (and simplified) fragment of the intersection crossing routine. It deals with the driver approaching an unsignaled intersection where obstacles mayor may not obstruct the view to the right, and where traffic may be heading towards the crossing point from the right. The diagrammed part of the program will check for approaching traffic from the right and act accordingly. Geometrically speaking a 

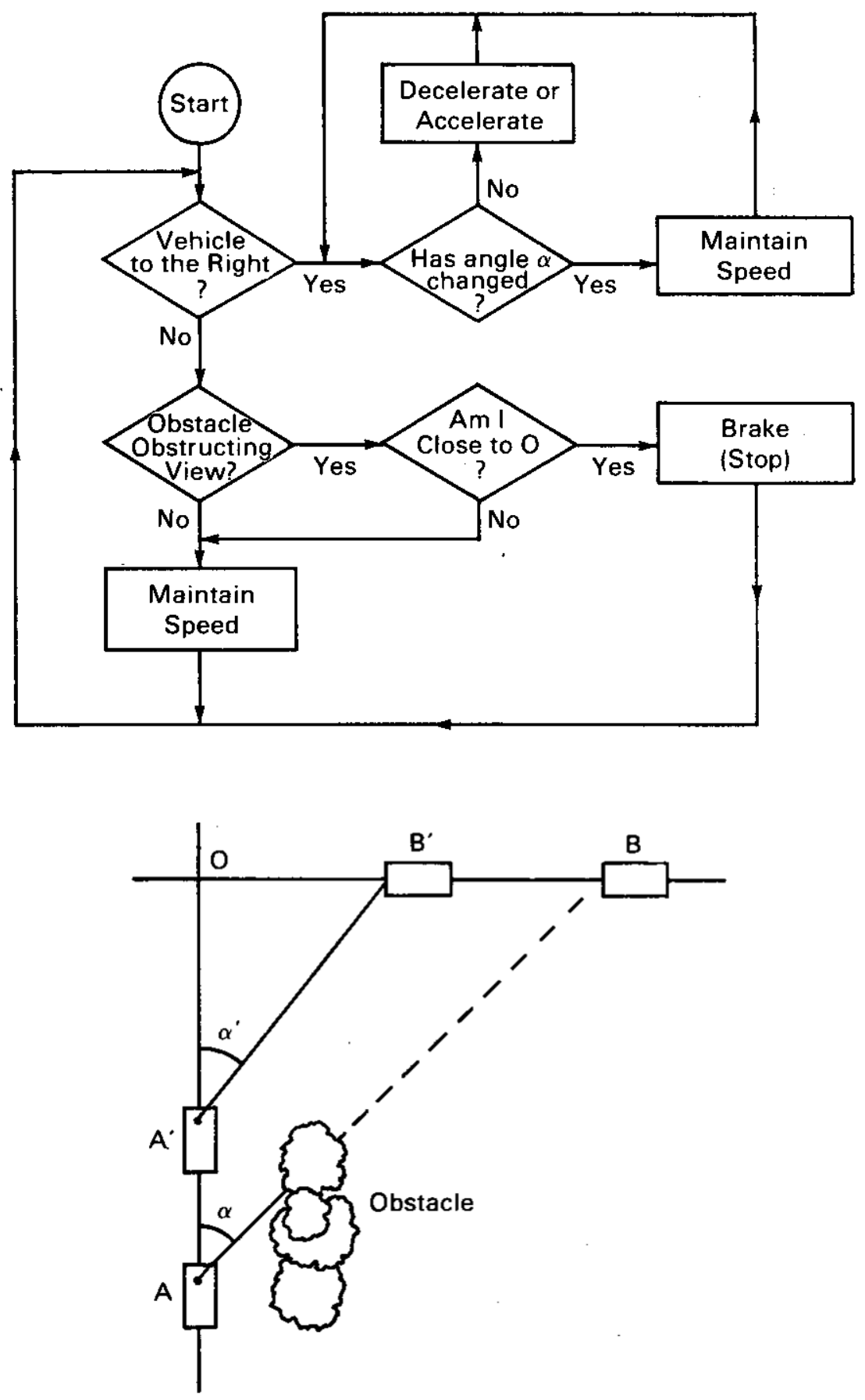

Figure 6 Approaching an intersection according to the information flow model of Kidd and Laughery (1964). 
collision will take place in this situation if the ratio of the distances between each vehicle and the point of intersection remains constant. The model acts on the information seen from the driver's seat, by repeatedly checking the visual angle between the point of intersection and the vehicle approaching from the right. When that angle remains constant over time, the driver will take action, since in that case a collision would be imminent.

Kidd and Laughery's model may be considered as an inventory of human factors data, connected in a sequential, task-dependent fashion. The various behaviors of both driver and vehicle are simulated dynamically, that is, behavioral parameters including reaction time delays allow the program to run in simulated time. Systematic variation of these parameters then allows one to obtain information about critical maneuvers in various road configurations and for various vehicle dynamics. And indeed the authors have carried out a number of studies along these lines.

In fact, Kidd and Laughery's model may be considered as a dynamic form of task analysis, a specification of which acts do follow certain others when particular conditions are fulfilled. They achieved a model covering a fair number of situations, and in its days it was certainly a very respectable simulation program.

If we put on our cognitive spectacles, however, we must conclude that this model has nothing to do with cognitive modeling. There is no spark of intelligence and no learning; there- is only data driven information processing: once the parameters for a particular run of the model have been determined the program will run strictly on the basis of fixed algorithms and further external inputs. If the outcome of a program run will be at all surprising, it is simply because of the complexity of the computation. The model does not even incorporate real priority interrupts. If a routine it happens to execute does not contain an instruction which tells it to check for crossing pedestrians, it will run over any number of them without even noticing.

If Kidd and Laughery's model did fail as a simulation of human behavior on the account of its rigid program structure, so did all subsequent models of its kind. That verdict includes DRIVEM, the DRIver-Vehicle Effectiveness Model developed by Wolf and Barrett (1978a, 1978b) for NHTSA. Like the earlier model DRIVEM has no intelligence, and its operations show no trace of learning. Like the other model its implements a number of driver related human factors data in a plausible way (Figure 7). What is new though, is the occurrence of "unexpected" Monte Carlo generated safety-related events. The model is implemented for eleven standard maneuvering scenarios such as merging, avoiding stationary objects and car following. Once a scenario is initialized certain critical events, which mayor may not occur, must be detected in order to avoid an accident. If an event is indeed detected a maneuver will be decided upon (also stochastically) and that maneuver will then be executed within the constraints imposed by the control dynamics of the simulated driver-vehicle system.

The presence of explicit maneuvering scenarios is a useful improvement over 


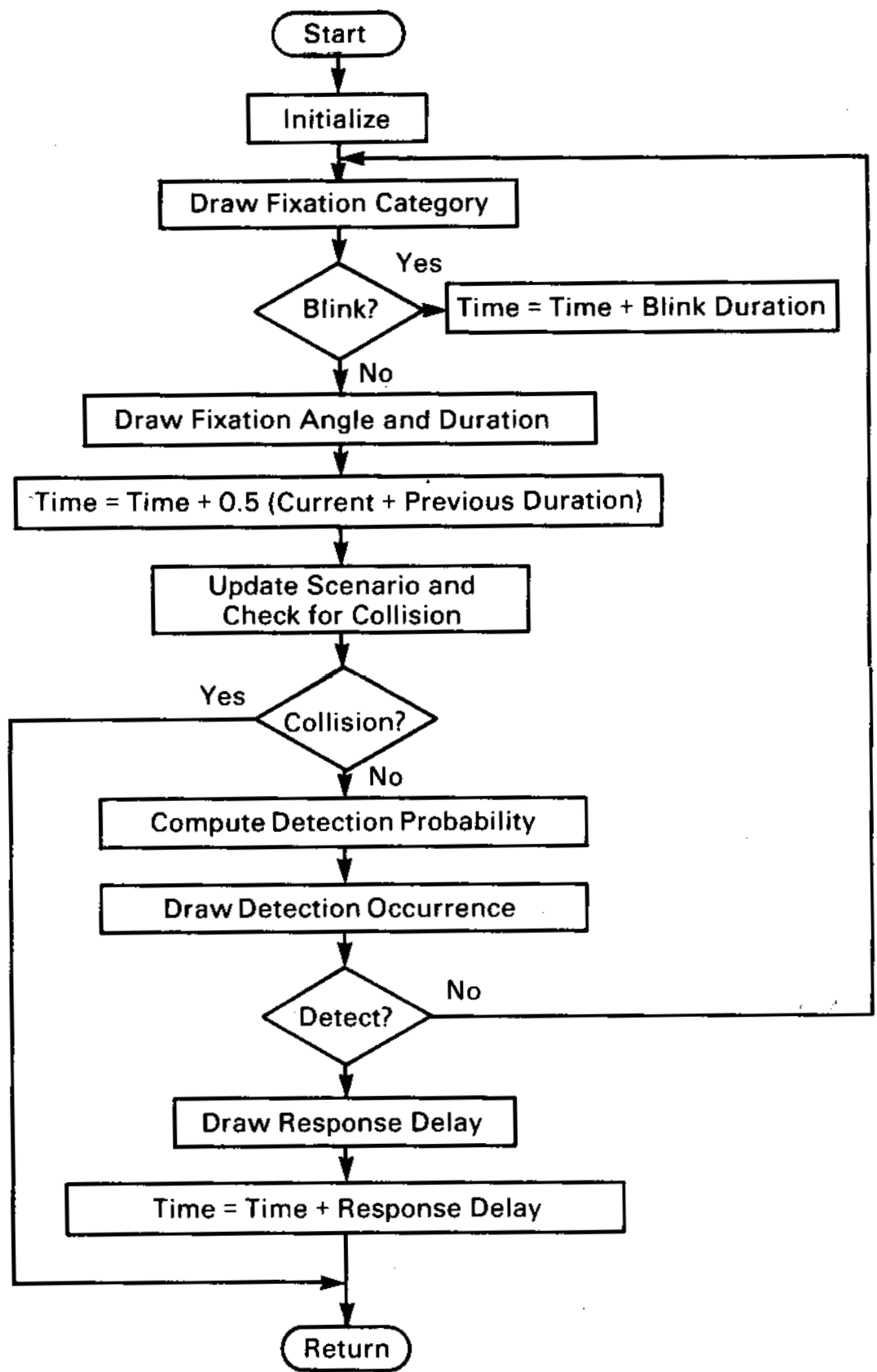

Figure 7 DRIVEM event detection control structure (from Wolf and Barrett, 1978a). 
Kidd and Laughery's model. It puts DRIVEM in the category of models that deal with both skill and tactics. The model as it is has been evaluated and rather severely criticized in a recent Workshop (Lieberman and Goldblatt, 1982). It is still very rudimentary and has not been validated against empirical results. Worse is, however, that it will sometimes produce highly implausible results which indicates that the system is not structured properly yet. The major recommendations of the workshop were to improve the model's event scanning and detection routines and to upgrade the model's data base; and further, to validate the model's goal priority parameters.

In summary, the information flow control model as a species was already around twenty years ago. Compared with the first attempts and given the progress made in behavioral simulation, it is surprising that more recent attempts are still following the old conception of passive simulation. The use of Monte Carlo techniques for stimulus- and decision selection does not alter this. This makes efforts such as NHTSA's recent development of the DRIVEM concept somewhat dinosauric: impressive perhaps, but on its way to extinction already.

\section{MODELS WITH MENTALITY}

In this category we find primarily those types of "motivational" model that make explicit assumptions about internal, sometimes called mental, states. This would seem to provide lots of insight in intelligent cognitive procedures and learning on the basis of internally generated rules. These expectations tend not yet to be fulfilled however. The problem appears to reside in the intentional character of many of these modes. They tend to discuss the products of cognitive functions (beliefs, emotions, intentions) rather than such functions themselves. In culinary language: there are cakes and there are recipes, and motivational models tend t6 have lots of cake-talk but little recipe-talk. Theoretically there is an unfortunately wide gap between surmising a certain belief structure in a person and constructing a system which will generate that belief structure on the basis of certain experiences.

This observation does not prevent the models to be discussed below from playing a substantial role in our efforts to establish a cognitive approach to driver behavior modeling. It only implies that the content of such models, that is, the beliefs, attitudes, perceived risk levels, etc., need to be translated into cognitive procedures. Problems involved in this translation are very central topics in contemporary theoretical discussion (e.g. Dennett, 1978; 1981; Flanagan, 1984; Michon, 1983).

Of the many motivational models that have been published between 1964 and now, I shall discuss only representative examples of each of the three major varieties of the species.

A fundamental concern of traffic psychology is traffic safety. Apparently it has been so fundamental that motivational models of road user behavior are almost synonymous with models of risk taking. In this respect they differ 
markedly from the ones considered thus far which, for the greater part, dealt with regular performance under normal conditions. The three model varieties to be discussed are: risk compensation, risk threshold, and risk avoidance. They differ primarily in the way in which they evaluate a perceived level of risk that is supposedly the control variable for the quality of driving performance.

Compensation Models - One of the first formulations of the risk compensation principle was Taylor's "risk-speed compensation model" (Taylor, 1964). Its basic tenet is: the larger the perceived risk is, the lower a driver's chosen speed will be. In short, the product of perceived risk and speed is constant. The accepted level of risk is individually determined, partly on the basis of external factors (time pressure) and partly on internal factors (age, perhaps neuroticism, etc.).

Taylor's model is purely descriptive and makes no claim whatever about the internal processes that playa role in compensatory behavior. As such it has no impact on cognitive modeling of driver behavior. A more serious point, however, which directly affects the value of the model is that it remains unclear what in fact is the effective stimulus determining the level of risk perceived. Actually, it shares this flaw with most other risk oriented models.

A substantial extension of the principle that drivers attempt to establish a balance between what happens on the road and their level of acceptable subjective risk can be found in Wilde's Risk Homeostasis Theory (Wilde, 1978; 1982; Wilde and Murdoch, 1982). It brought the germ of Taylor's compensatory model to fruition in a general theory of behavior under uncertainty, and on the face of it also appears to be explicit about the cognitive and motivational processes involved. Wilde's model assumes that the level of accepted subjective risk is a more or less stable personal parameter. Consequently, it predicts that attempts to increase traffic safety by improvements of road, vehicle, or even driving competence (skill training and experience), are likely to fail. Almost any improvement will in fact be compensated by faster or less cautious driving. Wilde's model stipulates instead the necessity of designing countermeasures that will lower the level of accepted subjective risk in a permanent fashion, and thus it leans heavily on the assumption that effective means of persuasion and enforcement can be found.

Wilde has succeeded in collecting an impressive body of evidence supporting his theory. As a result it has come under attack recently (e.g. McKenna, 1982, forthcoming; Huguenin, 1982; Hoyos, 1984; see also Wilde, 1984; Wilde and Kunkel, 1984). I shall not cover these criticisms since they are mostly directed at the plausibility of the theory in the light of empirical data. There is, however, one other point which is of more central concern to our present discussion.

Wilde's theory is ultimately formulated in terms of a servo-control model of individual behavior (Figure 8; see Figure 3 in Wilde (1982) for the thermostat analogy he is stipulating). Yet, this model is likely to have a meaning only at the aggregate level. The model's central tenet is that a road user's risk control behavior can only be influenced by affecting the level of perceived risk that is 


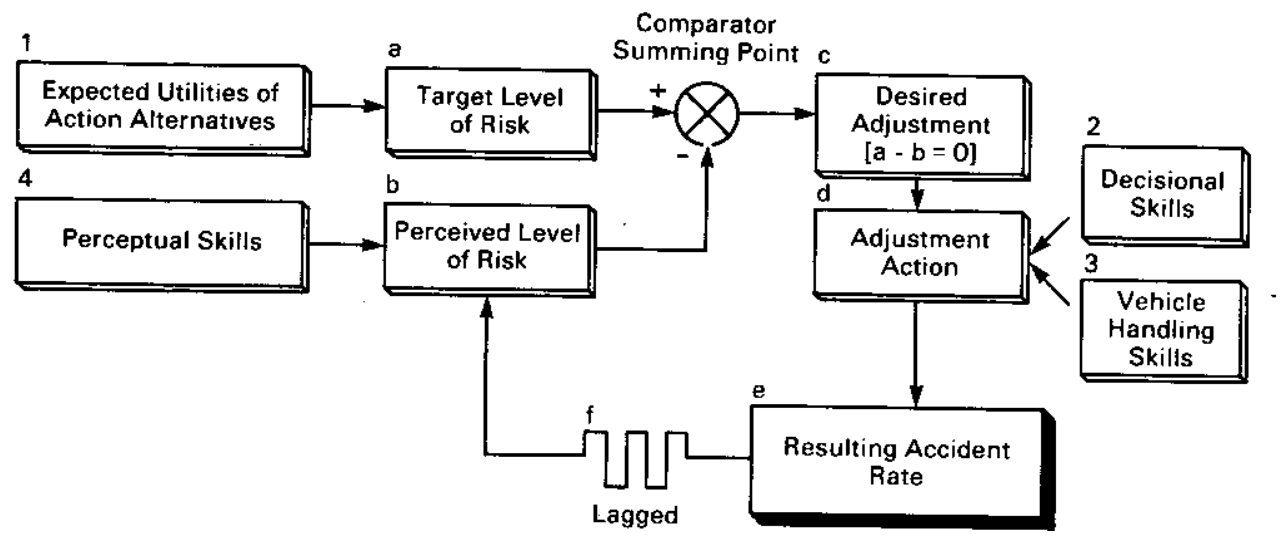

Figure 8 Wilde’s Risk Homeostasis model in its individual version (from Wilde, 1982).

acceptable to him or her: the target level. Influencing the target level, the only factor outside the model's control loop, entails, unfortunately, unknown and perhaps unknowable effects on the road user's belief structure, decision criteria and behavior routines, all of which are, irredeemably, elements within the control loop! In other words if I am overwhelmed by a plea for bringing my target risk level down to more humane proportions, I may indeed transform into an entirely different person, thereby achieving a complete and sudden resetting of my internal processing (e.g. Mandler, 1975; Brewer, 1974). This difficulty may well have been the reason why Wilde has recently capitalized on the socio-economic aspects of his theory. In fact Risk Homeostasis Theory seems to have become an economic theory more than a psychological one. Thus far it has had little to say about internal processes. Like older models it fails, for instance, to specify the discriminative stimulus for risk (McKenna, 1982). In the terms I used before: it contains mostly cake-talk and very little recipe-talk. Which is fine for those who like cake, but not for those, like Wilde, who would rather like to eat their cake and have it too.

Risk Threshold Theory - Klebelsberg (1971; 1977) adopted a somewhat different view to dealing with risk by postulating a control process that would enable a driver to maintain a stable balance between subjective, perceived safety (S), and objective, physically or statistically determined safety (0). If the system settles at a level where $\mathrm{S}=\mathrm{O}$, an ideal situation ensues. Traffic behavior is exactly commensurate with the prevailing circumstances and improvements in 0 , whenever they are perceived, will result in a corresponding improvement of S.

Individual road users differ in their personal balance between Sand 0, for a variety of reasons, cognitive, motivational, as well as physiological. Dangerous is any equilibrium where $\mathrm{S}>\mathrm{O}$, that is when the road user tends to judge situations safer than they in fact are. On the other hand, if $\mathbf{S}<\mathrm{O}$ there is a surplus safety margin. 


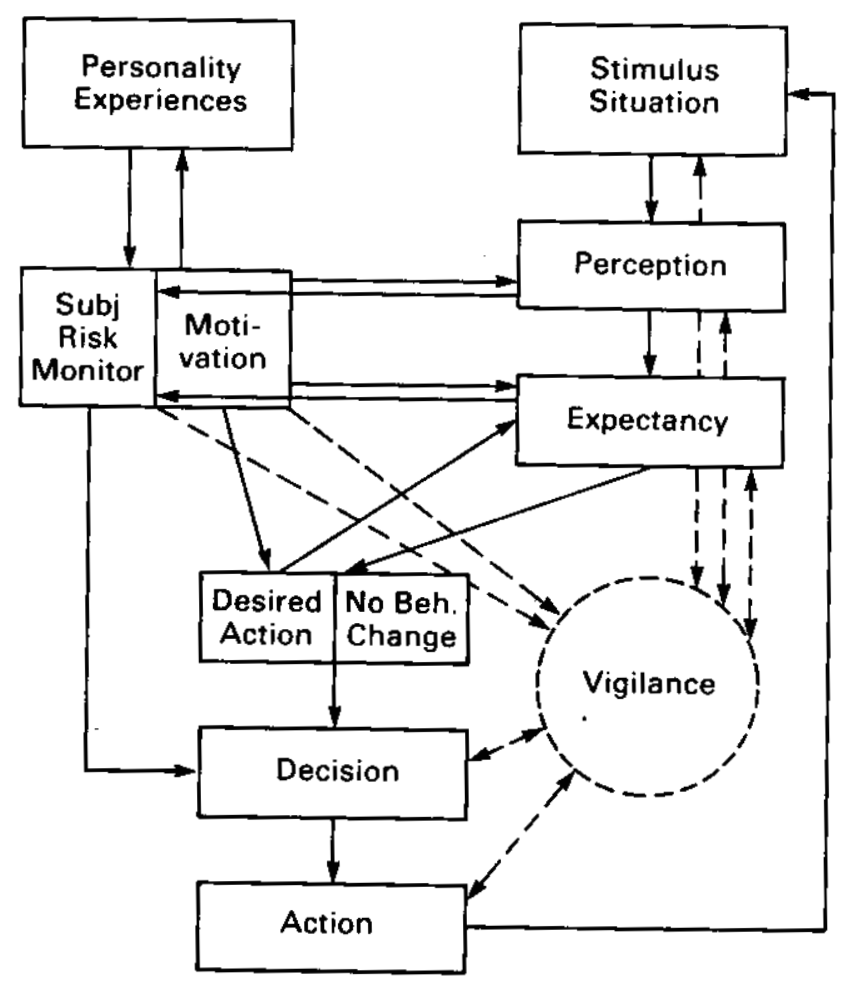

Figure 9 Näätänen \& Summala’s Risk Threshold model (after Näätänen and Summala, 1974).

A more advanced threshold model was proposed by Näätänen and Summala (1974; 1976). Their subjective risk control model (see Figure 9) states that perceived risk in traffic (R) depends on both the level of subjective probability of a hazardous event $(\mathrm{P})$ and the subjective importance of the consequences (B) of the event and, more specifically, on the product of these two factors: $\mathrm{R}=\mathrm{P} \times \mathrm{B}$. Behavior is assumed to be directly related to the level of $\mathrm{R}$. In most Circumstances $\mathrm{R}$ is perceived to be effectively equal to zero, that is, under normal road conditions traffic participants feel and act as if they are not running any "real" risk at all. In other words, there is a threshold for risk perception, and only if that threshold is exceeded, risk compensation mechanisms are called upon in an attempt to lower the prevailing risk level. This threshold is the pivotal control point in Näätänen and Summala's model. The authors argue that it is permanently too high in many road users, again for a variety of reasons, cognitive, motivational, or physiological.

In contrast with Wilde's position Näätänen and Summala consider their model to indicate that methods of influencing people by education, campaigns or enforcement are not effective. The risk perception threshold turns out to be highly resistant against such influences. Consequently, a genuine improvement of traffic safety should be expected only from better vehicles and better roads. 
Thus, Wilde (1978; 1982) and Näätänen and Summala (1976) yield contrary recommendations. This derives from the fact that Wilde assumes a continuous compensation of deviations from an accepted level of subjective risk, while Näätänen and Summala do, in fact, start from quality control assumptions: only when a tolerance limit is exceeded compensatory mechanisms will be put in operation.

The interactions between road users are mediated by distinctive and frequently subtle cues. Several attempts have been made to systematically describe the relations between such cues and the road user's behavior. Frequently these attempts take the form of ethological models, in which the authors seek to determine specific behavior eliciting stimulus configurations (Shor, 1964; Bliersbach and Dellen, 1980; Van der Molen, 1983). This approach, despite its methodological appeal, has not yet come to fruition, perhaps because most of the work has been carried out within the rather restrictive setting of improving the driver's perception of other road users (see Knapper, Leplat and Michon, 1980). A different line of research has fared much better because of its much larger generality. It is based on Fishbein and Ajzen's well known model for the relation between beliefs and attitudes on the one hand, and intentions and behavior on the other (Fishbein and Ajzen, 1975; Ajzen and Fishbein 1977). An example of this approach is a study currently underway at the Traffic Research Center in Groningen.

In this study (Vogel and Rothengatter, 1984) road user behavior is predicted through the application of Fishbein and Ajzen's model of reasoned action.

With regard to speeding behavior most drivers will tell you that they regard their own safety and that of others as an important factor in their speed choice. At the same time, however, drivers who habitually exceed speed limits do not consider their safety endangered by their speeding behavior- It appears therefore, that safety conditions hardly play a role in actual speed choice. Instead, other factors such as "pleasure in driving" do predict actual speed choice much more accurately. Drivers who travel for work purposes differ distinctly from private car users in the sense that they choose higher speeds and accept the consequential costs as trade-off against benefits such as reduction of travel time. "This suggests that their traffic behavior is firmly based on a rational weighting of cost and benefits, and consequently they are likely to prove very resistant against mass-media efforts to modify their behavior" (Vogel and Rothengatter, 1984).

The ultimate success of such models as Fishbein and Azjen's depends on the possibility to restate them in an explicit cognitive processing frame of reference. This requires that a functional process description be given that does indeed eliminate the intentional characteristics of the present formulation such as behavior being based on a rational weighting of cost and benefit (cf. Michon, 1980; 1984). Such a process-oriented description might possibly follow leads from, for instance, Mandler (1975).

The example concerns the frequently discussed but ill understood phenomenon of aggressive behavior in traffic (a.o. Hauber, 1977). In this context 
Bliersbach and Dellen (1980) reported-characteristically-that road users are able to discuss their emotions, but fail to understand the intensity of their feelings (see also Nisbett and Wilson, 1977; Ericsson and Simon, 1982; Hastie, 1983). Mandler (1975) suggested a further step toward a process description of aggressive behavior that appears eminently applicable to traffic aggression. Interruptions of an activity, according to Mandler, can be experienced as emotionally pleasant or unpleasant. Usually, however, interruptions have negative emotional significance, since they tend to interrupt precisely those activities which are the most adequate under the given circumstances (Note the hidden rationality assumption in the phrase the most adequate!). Assuming that traffic behavior is, first and foremost, going somewhere, an interruption of that goal-directed behavior is most likely to release strong negative affect.

The Threat Avoidance Model- In a recent study Fuller (1984) has put forward a model which incorporates a satisfactory number of characteristics of the preceding models, and which has the further advantage of being formulated in terms of a (behavioristic) paradigm: avoidance learning. As Fuller argues, "the experience of subjective risk is aversive and so drivers are motivated to escape from situations which elicit the experience or to avoid those situations."

The processes involved in dealing with risk, according to this model, are summarized in Figure 10.

On the basis of the behavior and the skill of the driver a situation will sometimes generate stimuli that are discriminative with respect to impending danger (boxes a and $\mathrm{h}$ in Figure 7). If such a stimulus presents itself (a) it will depend

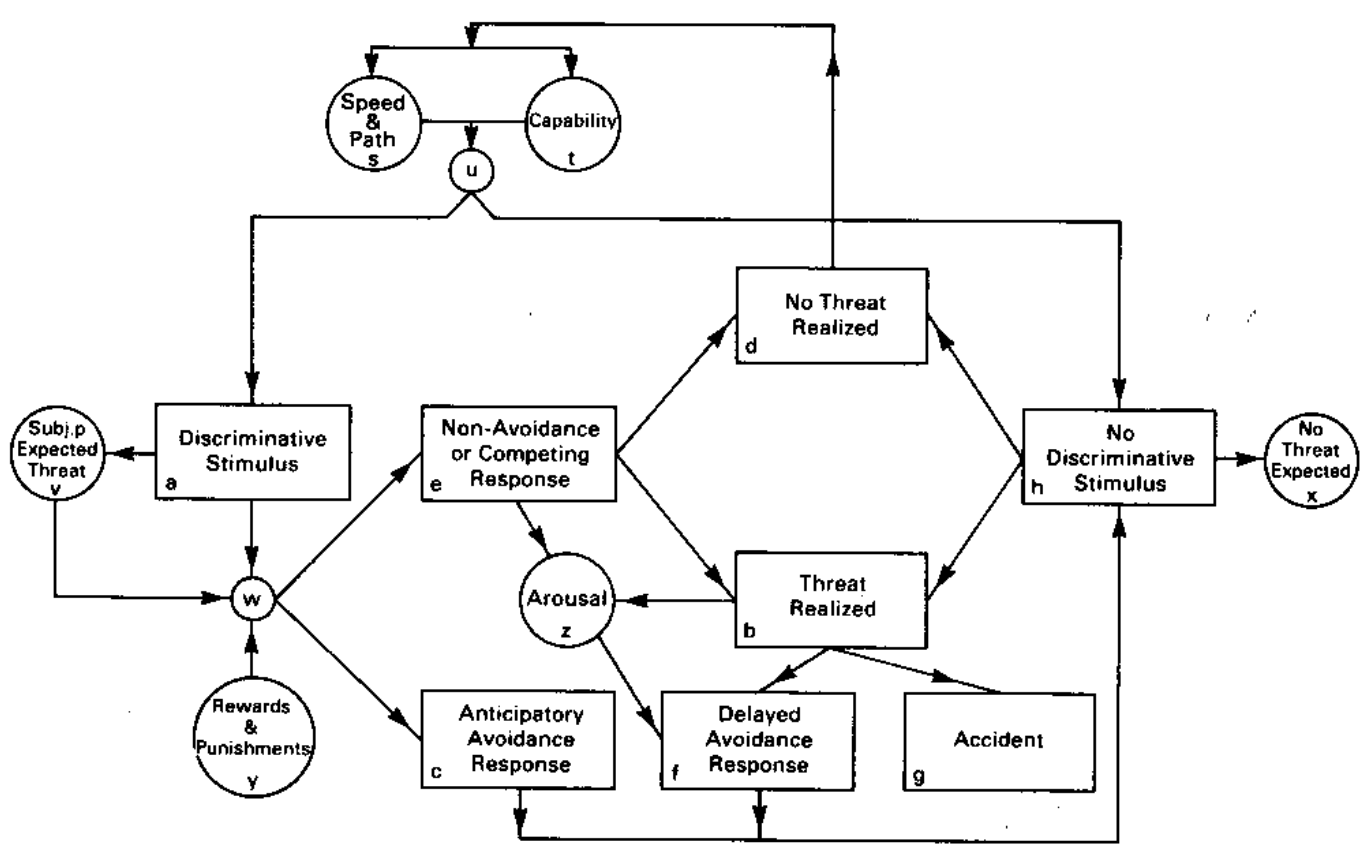

Figure 10 Fuller’s Risk Avoidance model (after Fuller, 1984) 
on a subject's expectations (v) motivations and utilities (y) whether an anticipatory avoidance response is selected (c) or not (e). In the first case we see the cautious driver eliminate the threatening stimulus as quickly as possible. In the second case a response will be selected which does not eliminate the threat. Of course not all threats will materialize (b vs. d), but if a discriminative stimulus does not disappear spontaneously several things may happen. The driver may sooner or later decide to perform a delayed avoidance response (t), either because he or she "chickens" due to the anxiety evoked by the stimulus (z), or the threat is realized, in which case there will be either a (successful) delayed avoidance response (t), or an accident (g).

It should be clear that Fuller's model provides a very general scheme for the behavior of drivers who are "dealing with danger" (Michon, 1980). Among other things the model implies the defensive driving concept. Also the difference between what Fuller (1984) calls the "typical Wilde driver" and the "typical Näätänen and Summala driver" does appear in this model as a different readiness to produce anticipatory avoidance responses.

Conceptually Fuller's model brings us closer to a cognitive processing model even though it is, in its present form, not quite explicit in this respect. However, it can cope with rule-based learning. For instance, in the learning phase a driver will eventually progress from delayed avoidance responses to anticipatory avoidance responses; this is occasionally trained explicitly, as in the training of Dutch police highway patrolmen.

"Some learning may perhaps be assimilated as a set of driving rules (e.g. 'never overtake on a blind corner') and some may come about vicariously through exposure to the actions of others." (Fuller 1984, p. 1146).

"The discriminative stimulus for, a potential aversive stimulus or threat ... under most conditions of driving ... is an integration of features projected into the future .... “ (o.c. p. 1147).

Such statements demonstrate that, despite certain behavioristic overtones, Fuller's model is leaning heavily on knowledge representation as the basis for driver performance.

\section{WHAT SHOULD WE DO?}

And thus we seem to be proceeding, at last, from adaptive control of behavior to adaptive control of thought. The question is simply whether there is a conceptual framework that will allow us to incorporate the various valuable concepts and relations that we should retain from the research reviewed in the preceding sections. A framework that can combine the explicit knowledge and action descriptions of the task analysis; the subtle adaptive control dynamics of servo- and information flow control, as well as the learning self organizing principles, hidden under the intentional formulations of the "motivational" models.

Fortunately such an approach is readily available. In their long and persistent pursuit of human problem solving and cognitive skill performance, Newell and Simon in particular have stressed the importance of a particular formulation for 
rule-based systems (such as humans), the so-called production system. Representing intelligent human activity by way of production systems has proven to be tremendously flexible and as such they offer an eminent formal basis for artificial intelligence, linguistics, and cognitive psychology. They may take various shapes; the following example represents the "typical Newell and Simon road crossing pedestrian" at an intersection (Newell and Simon, 1972; p. 33).

$\begin{array}{llll}\text { IF } & \text { traffic-light red } & \text { THEN } & \text { stop } \\ \text { IF } & \begin{array}{l}\text { traffic-light green } \\ \text { IF }\end{array} & \begin{array}{l}\text { THENe and left-foot- } \\ \text { on-pavement }\end{array} & \text { THEN } \\ \text { IF } & \begin{array}{l}\text { move and right-foot- } \\ \text { on-pavement }\end{array} & \text { THEN-with-right-foot } & \text { step-with-left-foot }\end{array}$

In the present context I shall follow the format proposed by Anderson (1980; 1981; 1982; 1983) who, incidentally also coined the term Adaptive Control of Thought (ACT). In this case a production system takes the form of a set of IFTHEN, condition-action statements which, when executed, will perform a certain task.

A Productive Step Towards a General Driver Behavior Model- I have been convinced for some time that it would be of great value for driver behavior research if we were to implement a driver behavior model in terms of a production system, and as a matter of fact I still cherish a dozen or so foolscap (what's in a name) pages with half-baked models, one of which, called SIMCA (for SIMulated CAr), almost got to the point where it would decide between a route containing one bridge that was occasionally open but if so, for a considerable time, and a route with many traffic lights and a grade railway crossing all of which would slow the driver down, but never very long. This effort failed for the reason so many models of driver behavior fail: the one-shot approach that is not based on a flexible, general theory of human cognition and a calculus which does embody that theory. An approach such as Anderson's offers, in my opinion just the kind of general theory we are looking for. In the following pages I shall first outline a few illustrative, but in no way systematic examples of the application of Anderson's stratagem vis-à-vis various aspects of the driving task.

Let me first introduce a novice driver attempting to cope with the good, old gearbox, which is still an essential part of the European automobile. Initially the subject will be told that, in order to shift the gear, he or she must execute a series of actions as summarized in the following production PI.

P1 IF

THEN the goal is to shift gear

and the instructor says "now"

release the gas pedal

and apply the clutch pedal

and move the gear stick to the neutral position 
and move the gear stick to the new position and release the clutch pedal while applying the gas pedal

In this initial stage of learning, it will be noticed, the novice has virtually no idea of why and when the gear is to be shifted. At the same time much explicit attention is devoted to the performance of the action part of the production. Moreover we will find that a difficulty is likely to arise when two action elements are to be combined (perhaps as a follow-up of a stage in which these elements were indeed executed independently. Indeed the attempt at integrating clutch and gas pedal actions is known to be literally a shocking experience for many beginning drivers. In later stages of learning how to drive this production will be complemented by others, and. at the same time a process of automatization sets in. The latter is the result of two general mechanisms-proceduralization and composition--that will ultimately lead to a very compact production as in $\mathrm{P} 2$.

P2 IF the goal is to shift gear then shift gear

Having reached the stage where gear shifting has become entirely trivial from the point of view of the (then expert) driver, deliberate control of action will only occur, except perhaps for a few minutes when the subject comes to drive a car of an unfamiliar make, or when there is a real emergency. At that point the driver will have to retrieve earlier, more knowledge based productions in order to be able to cope with the task. Otherwise the skill of gear shifting will have become part of our procedural repertoire, our "knowing how" as opposed to the earlier declarative s1age of "knowing that." Procedural knowledge as such is inaccessible to deliberate scrutiny: generally speaking we cannot explain how we perform skills such as skiing, piano playing or synchronized swimming, except by way of demonstration.

Just in case this example struck you as slightly trivial, let me go one step further and look at a somewhat more comprehensive set of gear shifting activities. What are the appropriate action goals in which PI, and later perhaps P2, are to be imbedded? Somewhat schematically, the following list suggests itself.

ACTION GOALS involving GEAR SHIFT

$\mathrm{Al}$ stand still (Gear $\mathrm{G}=\mathrm{O})$

A2 move backwards $(\mathrm{G}=\mathrm{R})$

A3 stop

A4 move forward at $20 \mathrm{~km} / \mathrm{h}(\mathrm{G}=\mathrm{I})$

AS move forward at $40 \mathrm{~km} / \mathrm{h}(\mathrm{G}=2)$

A6 move forward at $70 \mathrm{~km} / \mathrm{h}(\mathrm{G}=3)$

A7 move forward at $100 \mathrm{~km} / \mathrm{h}(\mathrm{G}=4)$

A8 accelerate

A9 decelerate

A 10 decelerate fast 


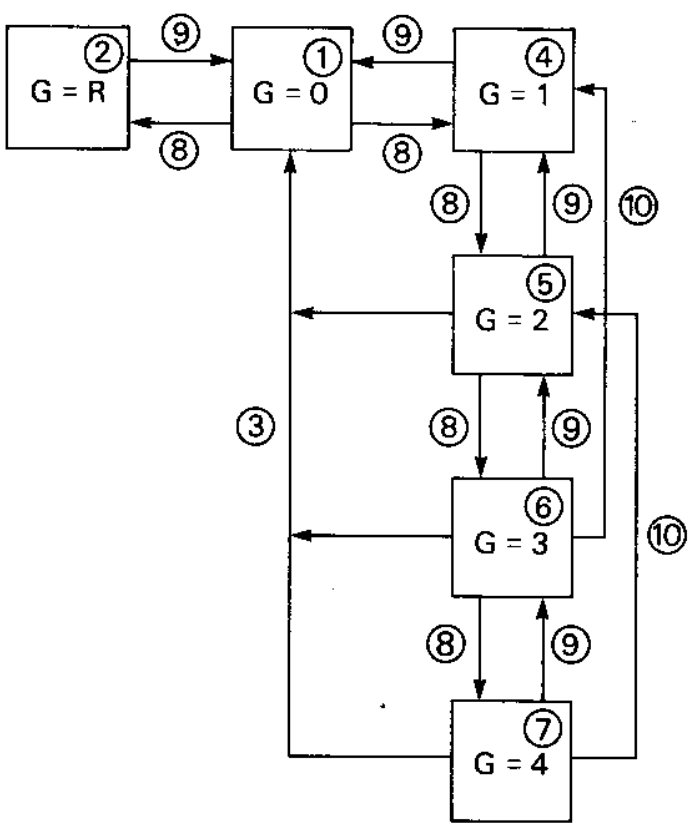

Figure 11 Action goal structure for gear shifting in European 4-shift automobile

This list covers, within reasonable bounds of 'proper' driving the major action goals that will induce gear shifting. They are not independent goals, however, and we can represent the interrelations as in Figure 11.

On this basis it is comparatively easy to build a consistent and complete production system that will cope with gear shifting under a variety of action goals. This system will include a number of productions such as the following, P3-P7.

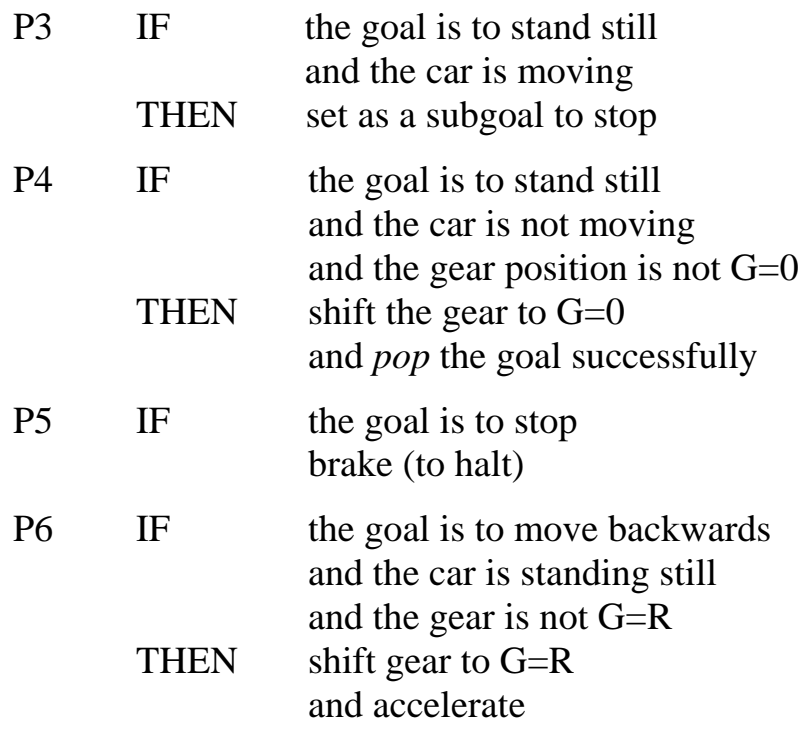


$\begin{array}{lll}\text { P7 IF } & \text { the goal is to move backwards } \\ \text { and the car is moving forward }\end{array}$

It will be superabundantly clear that the productions P3-P7 are not exhaustively describing what is needed according to Figure 11. A complete representation would, in fact consist of a production system that learns mainly by doing, by combining successive experiences in gradually more efficient and comprehensive productions. It would move from a declarative, fact-oriented, top-down knowledge stage, through an intermediate associative stage, to an automatic bottom-up performance stage (Fitts, 1963; Anderson 1983). In the course of this skill learning process performance would proceed from general and flexible but slow, to specific and rigid but fast.

Thus far I have concentrated entirely on a motor aspect of the driving task. The theory can, however, be worked out just as easily for the more cognitive aspects of driving, and perhaps even more easily. As an illustration, let us have a look at route finding, an important part of the maneuvering level of the driving task (e.g. Downs and Stea, 1973).

Some 15 years ago, a young French psychologist, Jean Pailhous published several papers-later to be combined into a single volume-about the mental maps and their use by Paris taxi drivers (Pailhous, 1970). I was fascinated by this project, and still am. It is in fact a closely knit outline of the cognitive processes that help a taxi driver for find his or her destination under almost every conceivable circumstance. In its elementary form the processes involved consist of three hierarchically related strategies as summarized in the following diagram:

Goal finding Procedures of Paris Taxi drivers

A. IF the destination is on the main grid of boulevards and avenues THEN go there along the shortest convenient route.

B. IF the destination is away from the main grid and the area is (perceptually) familiar THEN go to the point on the main grid that is closest to the destination and proceed from there to a point that is closer, using visual landmarks.

C. IF the destination is away from the main grid and the area is not (perceptually) familiar THEN go to the point on the main grid that is closest to the destination and proceed from there by minimizing the angle between current driving direction and the calculated direction of the destination.

It should be clear that expanding this algorithm into a set of productions should not be too difficult. In fact it requires little more than a system that will specify subgoals to be reached and what actions to take if detours have to be made, ascertaining that upon reaching a certain point in the network, the system will not get hung up in a loop. Two such productions would be the following 
P8 IF

IF the goal is to reach destination $\mathrm{D}$ from $\mathrm{P}$

and $\mathrm{D}$ is on the main grid

THEN reach $\mathrm{D}$ along a conveniently short route

P9 IF

the goal is to reach destination $\mathrm{D}$ from point $\mathrm{P}$

and $\mathrm{D}$ is not on the main grid

and $\mathrm{D}$ is not in the same area as $\mathrm{P}$

THEN set as a goal to reach D' such that D' is on the main grid

and the distance DD' is conveniently small.

In fact getting hung up is exactly what may happen to a real taxi driver. I clearly remember such an occasion, coming to Paris in the fall of 1971 with two colleagues to visit the laboratory where Pailhous was working at the time, when the taxi driver, who was evidently using strategy $\mathrm{C}$, barely missed the hotel. We caught a glimpse of the illuminated name sign of our hotel at some corner in an adjacent street, but that was all for a rather long time. In his increasing agony the driver could do no better than to circle around in wider and narrower spirals. This mothlike behavior must have gone on for at least a quarter of an hour and all this time we must have been within 250 or 300 meters from our destination.

The following pair of productions would seem to add an important perspective to the taxi driver model. (P10, incidentally, would seem to be a good production for any taxi driver model whatever).

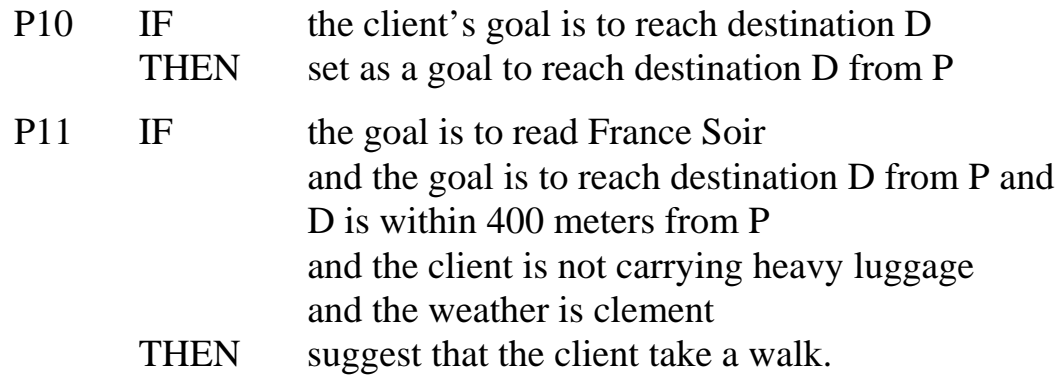

Such productions introduce motivational and high level travel planning into the driver model in a consistent and homogeneous way: the formal apparatus remains exactly the same, but higher goal levels are introduced, in this particular case a recreational one.

I return for a moment to Fuller's threat avoidance model. As we saw already, it would seem possible, in Fuller's own opinion, to subsume the typical "Näätänen and Summala driver" and the typical "Wilde driver" under his model as shown in Figure 10 "The typical Näätänen and Summala driver would follow the path from circle $w$ (integration) to box $c$ (anticipatory avoidance [response, AAR]), thereby minimizing the risk of accident ( ... ). Such a driver would become only objectively risky when factors affected either the adequacy with which dis- 
criminative stimuli were recognized or the adequacy of the avoidance response itself. On the other hand, the typical Wilde driver would presumably follow the path from circle $w$ to box $e$ (non-avoidance or competing response) intentionally delaying an avoidance response as far as the point where a target level of subjective risk of accident was reached.” (Fuller, 1984, p. 1153). The following two productions catch this distinction.

$\begin{array}{lll}\text { P12 IF } & \begin{array}{l}\text { a discriminative stimulus is observed } \\ \text { and a threat expectation is associated with it } \\ \text { execute AAR } \\ \text { and delay any higher utility responses }\end{array} \\ \text { Pl3 } & \text { IF } & \begin{array}{l}\text { a discriminative stimulus is observed } \\ \text { and a threat expectation is associated with it } \\ \text { and the target risk level is not exceeded } \\ \text { and there are responses of greater utility than } \\ \text { the appropriate AAR } \\ \text { executive NAR or CR with highest utility and } \\ \text { increment perceived level of aversive stimulation }\end{array}\end{array}$

In this brief survey I have attempted to indicate some of the potential of a cognitive, production oriented approach to driver behavior modeling. Now let us elaborate on why I think this approach comes indeed close to what we should do, keeping in mind what we already achieved in the past twenty years.

The Intrinsic Flexibility of Production Systems - Production systems, first suggested in 1947 by the mathematician Post, are among the most powerful techniques for describing complex computational or symbol processing systems. Recently they have become popular among psychological researchers, especially in psycholinguistics, problem solving and reasoning. They provide a consistent, and metaphysically neutral, formalism which can handle internal states of the organism. But unlike earlier versions of "neutralism," they solve the problem that mental states would seem to be incapable of triggering observable behavior. Thus, for instance the animal psychologist E.C. Tolman assumed around 1935 that rats can deal with complex spatial mazes becausejust like Paris taxi drivers - they build "mental maps" of their environment. The production concept eliminates an often cited objection of Guthrie (1952; p. 143) to Tolman's theory, that it left the rat "buried in thought and inaction." The condition-action pairs of productions introduce the required connection between thought and action.

Early attempts at production system descriptions of complex human behavior, such as the pedestrian example from Newell and Simon (1972) shown above required a strict order (IF $x$ THEN $y$ ELSE next production). The reason was simply that these attempts said little or nothing at all about the control structure that would choose and execute the productions in a correct order. Such recent developments as the system proposed by Anderson contain elaborate mechanisms for deciding which production will be selected next, as well as when and how certain productions will become "proceduralized" or "com- 
posed." Proceduralization is the adaptation of productions such that they can be retrieved fast when they are required by the circumstances, even if the part of long term memory to which they belong is inactive at that time. Composition is, as we have already seen, the combination of two or more explicit productions into more efficient shorter productions.

The selection of productions, and their order of execution is no trivial matter when the choice is not determined algorithmically. It is possible to conceive of various criteria, whose plausibility is determined by the plausibility of the psychological theory of which they are a part. In his recent exposition Anderson (1983) distinguishes five such criteria: degree of match, production strength, data refractoriness, production specificity, and goal dominance. The first two are straight-forward. If two or more productions are appropriate then the production best matching the condition will be executed. Similarly, other things being equal, the strongest (e.g. overlearned) production will be selected. Data refractoriness helps to avoid loops because it will prevent productions to operate on the same data twice (unless perhaps after a certain delay). Production specificity implies that of two equally applicable productions the most specific one will take precedence. And finally, goal dominance hinges on the assumption that of the goals that are currently in the process of being pursued, only one can be active at any particular moment. Productions that are pertinent to this goal take precedence over productions which are pertinent to other goals. The selection process based on these five principles is controlled simply by the outcome of continuous data-flow pattern matching (Anderson, 1983; p. 81). If, for instance, in the course of pursuing a set of goals-such as reaching a destination in a large metropolis-I loose track of where I am relative to these goals, the production selection will become less structural(goal dominance giving way to degree of match), and as a result my behavior will tend to become less structured too and more data driven (opportunistic).

One may also ask how complex a model of the driver built along the lines drawn in this paper will have to be in order to display a sufficiently broad spectrum of realistic driving behaviors. If we assume that such a model will at least have to cover the integral task analysis of McKnight and Adams (1970a, 1970b; McKnight and Hundt, 1971) and that each of their elementary tasks will probably represent more than one production, then it will be clear that this model is not nearly going to meet Reid's criterion that a driver model "should have a structure that is not difficult or expensive to implement” (Reid, 1983; p. 23). Herbert Simon has frequently argued that it takes roughly 50000 meaningful "chunks" of knowledge, such as productions, to achieve a level of mastery in any skill, and perhaps as many as 200000 to become a genuine expert. Anderson (1983) offers as his best guess between 10000 for one skill and 10000000 productions altogether. Any reasonable model of the driver, that is, one which will incorporate all three levels of road user performance control—strategical, tactical and operational-must therefore probably embody at least between 10000 and 50000 productions. 


\section{CONCLUSIONS}

Now, let us try to balance our account and answer the initial questions once more, with feeling.

Once More: What Do We Know? - Psychological research has undergone a rather drastic and fundamental change. Twenty years ago researchers were excited by the new possibilities of information processing models which relied heavily on the communication channel and the thermostat analogy. Driver modeling by and large was part of this "scene." Now the scene has changed towards representational and computational theories and models. But driver behavior modeling has not kept up. The various model types that I reviewed lack in one or more of the following respects. They are generally bottom up, not capable of learning, or if they contain top down elements they do not specify the processes involved and consequently cannot be validated. They do not specify the structure of the internal models which drivers must hold in their mind (or their feedback circuits (see Wonham, 1976), or if they do they tend to be simplistic. No model that treats driver behavior from a monocausal point of view will remain in business very much longer.

The cognitive approach, whose surface I have just barely begun to scratch constitutes a considerable step forward in the modeling of driver behavior. More specifically, production systems appear to embody just the required flexibility for coping with complex tasks such as driving an automobile. Why is this?

c. The approach is general. The basic formal apparatus is that of the theory of computation and its various related fields of cognitive science. Such methodological ties exist also between research and control theory and have proved to be extremely profitable. Production systems can deal with many levels of specification-general and detailed-and at any level they can be interfaced with other types of mechanisms, algorithms and continuous adaptive control circuits, without loss of generality.

d. Not only can productions be interfaced at the lowest functional level with, say, servo-control loops. It is also possible to incorporate higher control mechanisms, that is, schemata or "scenarios" (Schank, 1982; Anderson; 1983), including those representing motivational and trait related aspects of driver behavior. This would enable us to generate process formulations of the avoidance behavior described by Fuller (1984). Driver taxonomies such as Quenault's $(1965,1968)$ could also be restated in terms of productions.

e. The approach is generative and accepts any mixture of top down and bottom up processing. In this respect it differs from all previous models which may perform well to the extent they are bottom up (or data driven) although this is not necessarily the case. To the extent existing models claim to be top down, they either are insufficiently determined to be implemented in, say, a computer program, or the implementation is trivial as a result of the hideous homunculi that are concealed in the model's for- 
mulation. Production systems, on the other hand function at least partly top down; as learning systems they possess just the required level of adaptive control for modeling substantial domains of human behavior and human thought.

d. The approach is essentially at the individual level as far as its performance is concerned, but it is general to the extent that it describes human cognitive competence. That is, when applied to driving it would be stated as a general theory of driver behavior, but when put to work it will generate an individual driver's history, depending on its learning experiences. In order to obtain aggregate data representing a population of drivers several such histories would have to be obtained. This will be a time consuming affair, but it allows a detailed insight in the effect of certain environmental conditions and learning experiences. It would, for instance, become possible to check the plausibility of a number of features of Wilde's model taken as an individual model.

As a theory of competence a driver behavior model based on assumptions such as I have presented could be very simple; as a performance theory it can become extremely complex if we wish it to.

Once More: What Should We Do?-It does appear that for the last thirty pages we have already been moving in the direction I said we ought to be heading for (see p. 485). Let me propose one more step. In straightforward terms this step amounts to establishing a working party or research group of those who by concerted action, would be willing to contribute to the development of a comprehensive cognitive-that is, representational and computationalmodel of the driver.

The group would, first of all, have to design performance criteria, so that we may recognize what constitutes adequate performance of such a model. Secondly, a common formal language will have to be developed, or adopted if one already exists. Perhaps Anderson's approach would be a suitable option, although I used it to illustrate rather than to propose it as the one and only road to bliss. In any case the approach that is to be adopted must allow strict modularity. That is, parts of the driving task that are not incorporated from the beginning should be added without requiring changes in the overall control structure. Rules and factual knowledge to be added should therefore have standard formats. A third task for the group would be to decide upon a set of representative behaviors at different levels in the control hierarchy. These would have to be the tasks that are recognized as central to the driving task. They would become so much as the benchmark tests which allow testing the model against empirical results as obtained by over the road and simulator studies and laboratory experiments.

Briefly said this amounts to developing the language and the control structure (operating system) in and by which to formulate future models of driver behavior, including the criteria by which to judge such models. 
Only then it would be possible to have a symposium on traffic safety and driving behavior that is "concerned with what humans actually do while exposed to various traffic environments as opposed to what humans are capable of doing," which the conveners of the present symposium intended their meeting to be. This does not imply, of course, that the present meeting was not successful; after all we did start on the new track!

\section{REFERENCES}

ACRIT (Advisory Committee on Research of Information Transfer). Informatieverzorging: Onderzoek onderzocht. Rapport van de Ministeriële Verkenningscommissie Onderzoek Informatieverzorging. Den Haag: Staatsdrukkerij en Uitgeverij, 1984.

Ajzen, I., and Fishbein, M., Attitude-behavior relations: a theoretical analysis and review of empirical research. Psychological Bulletin 84, 888-918, 1977.

Alberti, E., and Belli, G., Contributions to the Boltzmann-like approach fro traffic flow: A model for concentration dependent driving programs. Transportation Research, 12, 33-42, 1978.

Anderson, J.R, Cognitive psychology and its implications. San Francisco: Freeman, 1980.

Anderson, J.R (ed.), Cognitive skills and their acquisition. Hillsdale, NJ: Erlbaum, 1981.

Anderson, J.R, Acquisition of cognitive skill. Psychological Review, 89, 369406, 1982.

Anderson, J.R, The architecture of cognition. Cambridge, MA: Harvard University Press, 1983.

Bliersbach, G., and Dellen, R.G., Interaction conflicts and interaction patterns in traffic situations. International Review of Applied Psychology, 29, 475-490, 1980.

Brewer, W.F., There is no convincing evidence for operant or classical conditioning in adult humans. In: W.B. Weimer, and D.S. Palermo (eds.), Cognition and the symbolic processes. Hillsdale, NJ: Erlbaum, 1974.

Conger, J.J., Gaskill, H.S., Gladd, D.D., Hassell, L., Rainey, R.V. and Sawrey, D.W.L., Psychological and psychophysical factors in motor vehicle accidents. Journal of the American Medical Association 169, pp. 1581-1587, 1959.

Crossman, E.R.F.W., and Szostak, H., Man-machine models for car steering.

Proceedings of the Fourth Annual Conference on Manual Control. NASA Report SP 192, pp.171-195. Washington DC, 1968.

Dennett, D.C., Brainstorms: Philosophical essays on mind and psychology. Montgomery, VT: Bradford Books, 1978.

Dennett, D.C., Three kinds of intentional psychology. In: R Healy (ed.), Reduction, time and reality: studies in the philosophy of the natural sciences. Cambridge: Cambridge University Press, 1981.

Downs, RM., and Stea, D. (eds.), Image and environment: Cognitive mapping and spatial behavior. Chicago: Aldine, 1973. 
Edie, L.C., and Foote, R.S., Effect of shock waves on tunnel traffic flow. Highway Research Board, Proceedings Vol. 39,1960.

Ericsson, K.A. and Simon, H.A., Verbal reports as data. Psychological Review, 87, 215-251,1980.

Fell, J.C., A motor vehicle accident causal system: The human element. Human Factors, 18, 85-94, 1976.

Fishbein, M., and Ajzen, I. Belief, attitude, intention and behavior: an introduction to theory and research. Reading, MA: Addison-Wesley, 1975.

Fitts, P.M., Perceptual-motor skill learning. In: A.W. Melton (ed.), Categories of human learning. New York: Academic Press, 1963.

Flanagan, J., The science of the mind. Cambridge, MA: Bradford Books/MIT Press, 1984.

Fleishman, EA., Performance assessment based on an empirically derived task taxonomy. Human Factors, 9, 349-366, 1967.

Fleishman, E.A. Toward a taxonomy of human performance. American Psychologist, 30, 1127-1149, 1975.

Forbes, T.W. (ed.), Human factors in highway traffic safety research. New York: Wiley-Interscience, 1972.

Fuller, R., A conceptualization of driver behavior as threat avoidance. Ergonomics, 27, 1139-1155, 1984.

Gibson, J.J., The senses considered as perceptual systems. Boston, MA: Houghton Mifflin, 1966.

Greenberg, H., An analysis of traffic flow. Operations Research, 1959, 7, ...

Guthrie, E.R., The psychology of learning. New York: Harper and Row, 1952.

Hastie, R., Social inference. Annual Review of Psychology 1983, 34, 511-542.

Hauber, A., Gedrag van mensen in beweging: onderzoek naar agressie in het verkeer en fraude bij het openbaar vervoer. Dissertation, University of Leiden, 1977.

Herman, R., Montroll, E, Potts, R., and Rothery, R., Traffic dynamics: Analysis of stability in car following. Operations Research, 7, ..., 1959.

Hoyos, C. Graf, Stellungnahme zu einer Diskussion über die Theorie der Risikokompensation. Zeitschrift für Verkehrssicherheit, 30, 61-62, 1984.

Huguenin, R.D., Zur Problematik von Risikohomeostasetheorien in der Verkehrspsychologie. Zeitschrift für Verkehrssicherheit, 28, 180-187, 1982.

Janssen, W.H., Routeplanning en geleiding: Een literatuurstudie. Report IZF 1979 C-13. Soesterberg (The Netherlands): Institute for Perception TNO, 1979.

Kidd, E.A., and Laughery, K.R., A computer model of driving behavior: The highway intersection situation. Buffalo, NY: Cornell Aeronautical Laboratories, Report or. VI-1843-V-l, 1964.

Klebelsberg, D., Subjektive und objektive Sicherheit im Strassenverkehr als Aufgabe für die Verkehrssicherheitsarbeit. Schriftenreihe der Deutschen Verkehrswacht 51, 3-12, 1971.

Klebelsberg, D. Das Modell der subjektiven und objektiven Sicherheit. Schweizerische Zeitschrift für Psychologie und ihre Anwendungen 36,285-294, 1977. 
Knapper, C.K., Leplat, J., and Michon, J.A. (eds.), Special issue on driving behaviour. International Review of Applied Psychology, 29, 397-528, 1980.

Koenderink, J.J., and Van Doorne, A.J., How an ambulant observer can construct a model of the environment from the geometrical structure of the visual inflow. Kybernetik 19, 224-247, 1978.

Levelt, W.J .M., Monitoring and self-repair in speech. Cognition, 14, ... 1983.

Lieberman, E.B., and Goldblatt, R, A review of the driver-vehicle effectiveness (DRIVEM) model. New York: KLD Associates Inc., Report, 1981.

Mandler, G., Mind and emotion. New York: Wiley, 1975.

Margulis, L., and Schwartz, K. V., Five kingdoms: An illustrated guide to the phyla of life on earth. San Francisco: Freeman, 1982.

McKenna, F., The human factor in driving accidents: An overview of approaches and problems. Ergonomics 25, 867-877, 1982.

McKenna, F., Accident proneness: a conceptual analysis. Accident Analysis and Prevention 15, 65-72, 1983.

McKenna, F., Do safety measures really work?: An examination of risk homeostasis theory. Ergonomics, forthcoming.

McKnight, A.J., and Adams. B.B., Driver education task analysis. Volume I: Task descriptions. Alexandria, VA: Human Resources Research Organization, Final Report, Contract No FH 11-7336, 1970.

McKnight, A.J., and Adams, B.B., Driver education task analysis. Volume II: Task analysis methods. Alexandria, VA: Human Resources Research Organization, Final Report, Contract No FH 11-7336, 1970.

McKnight, A.J., and Hundt, A.G., Driver education task analysis. Volume III: Instructional Objectives. Alexandria, VA: Human Resources Research Organization, Final Report, Contract No FH 11-7336, 1971.

McRuer, D.T., and Weir, D.H., Theory of manual vehicular control. Ergonomics, 12, 599-633, 1969.

McRuer, D.T., Allen, RW., Weir, D.H., and Klein, RH., New results in driver steering control models. Human Factors 19, 381-397, 1977.

Michon, J.A. Psychonomie onderweg (Inaugural Lecture). Groningen: WoltersNoordhoff, 1971.

Michon J .A., The mutual impacts of transportation and human behavior. In: P. Stringer and H. Wenzel (eds.), Transportation planning for a better environment, pp. 221-236. New York: Plenum Press, 1976.

Michon, J.A., Dealing with danger: Report of the European Commission MRC Workshop on physiological and psychological factors in performance under hazardous conditions, Gieten, The Netherlands, 23-25 May, 1978. Haren (The Netherlands): Traffic Research Center, University of Groningen, Report VK 7901,1979.

Michon, J.A., Telling road users who they are and what they do: can they profit? International Review of Applied Psychology 29,399-414, 1980.

Michon, J.A., Over de metatheoretische grondslagen van de psychonomie. In: J.G.W. Raaijmakers, P.T.W. Hudson, and A.H. Wertheim (eds.), Metatheoretische aspecten van de psychonomie. Deventer: Van Loghum Slaterus, 1983. 
Michon, J.A., Traffic and mobility. In: P.J.D. Drenth, H. Thierry, P.J. Willems, and Ch.J. de Wolff (eds.), Handbook of work and organizational psychology, Vol. 2, New York: Wiley, 1984, pp 1165-1196.

Michon, J.A. and Van der Molen, H.H., Sociale verkeerskunde: verslag van het symposium gehouden in Groningen, November 1974. Den Haag: ANWB, 1976.

Miller, T.M., and Schuster, D.H., Long-term predictability of driver behavior. Accident Analysis and Prevention 1983, 15, 11-22.

Näätänen, R., and Summala, H., A model for the role of motivational factors in drivers' decision-making. Accident Analysis and Prevention, 1974, 6, 243-261.

Näätänen, R., and Summala, H., Road user behavior and traffic accidents. Amsterdam: North Holland Publishing Cy, 1976.

Newell, A., and Simon, H.A., Human problem solving. Englewood Cliffs, NJ.: Prentice-Hall, 1972.

Nisbett, R.E., and Wilson, T.D., Telling more than we can know. Psychological Review, 84, 231-259,1977.

Norman, D.A., Categorization of action slips. Psychological Review, 88, 1-15, 1981.

Pailhous, J., La représentation de l'espace urbain. Paris: Presses Universitaires de France, 1970.

Perchonok, K., Accident cause analysis. Report prepared for the US Department of Transportation, DOT HS 800 716. Buffalo, NY: Cornell Aeronautical Laboratory, 1972.

Preyss, A.E., A theory and model of human learning behavior in a manual control task. NASA Contractor Report, NASA CR-1124. Cambridge, MA: MIT, 1968.

Quenault, S.W., Driver behavior, safe and unsafe drivers. Transportation and Road Research Laboratory, Crowthorne, U.K.: Report Nr. LR 70, 1967.

Quenault, S.W., Golby, C.W., and Pryer, P.M., Age groups and accident ratedriving behavior and attitudes. Transportation and Road Research Laboratory, Crowthorne, U.K.: Report Nr. LR 167, 1968.

Reid, L.D., Survey of recent driving steering behavior models suited to accident investigations. Accident Analysis and Prevention, 15, 23-40, 1983.

Riemersma, J.J., Visual control during straight road driving. Acta Psychologica, 48,215-225, 1981.

Schank, R.C., Dynamic memory: A theory of reminding and learning in computers and people. Cambridge: Cambridge University Press, 1982.

Shaw, L., and Sichel, H., Accident proneness. Oxford: Pergamon Press, 1971. Shinar, D., Psychology on the road: the human factor in traffic safety. New York: Wiley, 1978.

Shor, R.E., Shared patterns of nonverbal expectations in automobile driving. Journal of Social Psychology, 62, 155-163, 1964.

Taylor, D.H. Drivers' galvanic skin response and the risk of accident. Ergonomics, 7, 439-451, 1964. 
Van der Molen, H.H., Rothengatter, J.A. and Vinjé, M.P., Blueprint of an analysis of the pedestrian's task-I. Method of analysis. Accident Analysis and Prevention, 13, 175-192, .1981.

Van der Molen, H.H., Pedestrian ethology: unobtrusive observations of child and adult road-crossing behaviour in the framework of the development of a child pedestrian training programme. Haren (The Netherlands): Traffic Research Center, University of Groningen, 1983.

Veling, I., Measuring driving knowledge. Accident Analysis and Prevention, 14, 8186, 1982.

Weir, D.H., and McRuer, D.T., A theory for driver steering control of motor vehicles. In: Road user characteristics, Highway Research Record, nr. 247, 7-28, 1968.

Wertheim, A.H., Wagenaar, W.A., and Leibowitz, H.W. (eds.), Tutorials on motion perception. New York: Plenum Press, 1982.

Wierwille, W.W., and Gagne, G.A., Non-linear and time varying dynamical models of human operators in manual control systems. Human Factors, 8, 97-120, 1966.

Wilde, G.J.S., Theorie der Risikokompensation der Unfallsverursachung und ihre praktische Folgerungen fur die Unfallverhmung. Hefte zur Unfallheilkunde 130, 134-156, 1978.

Wilde, G.J.S., The theory of risk homeostasis: implications for safety and health. Risk Analysis, 2, 209-225, 1982.

Wilde, G.J.S., Evidence refuting the theory of risk homeostasis?: a rejoinder to Frank P. McKenna. Ergonomics, 27, 297-304, 1984.

Wilde, G.J.S., and Murdoch, P., Incentive systems for accident-free and violencefree driving in the general population. Ergonomics, 25, 879-890, 1982.

Wohl, M., and Martin, B.V., Traffic systems analysis for engineers and planners. New York: McGraw-Hill, 1967.

Wolf, J.D., and Barrett, M.F., Driver-vehicle effectiveness model; volume I: Final report. Washington, DC: Department of Transportation. Report No DOT HS 804 337, 1978 (a).

Wolf, J.D., and Barrett, M.F., Driver-vehicle effectiveness model; volume II: Appendices. Washington, DC: Department of Transportation. Report No DOT HS 804 338, 1978 (b).

Wonham, W.M., Towards an abstract internal model principle. IEEE Transactions on Systems, Man and Cybernetics, 6, 735-740, 1976.

Young, L.R., On adaptive manual control. Ergonomics, 12, 635-674, 1969. 